\title{
Определение области термической стабильности размера и фазового состава наночастиц полупроводникового сульфида серебра
}

\author{
(С) С.И. Садовников ${ }^{1}$, Э.Г. Вовкотруб ${ }^{2}$ \\ ${ }^{1}$ Институт химии твердого тела Уральского отделения Российской академии наук, \\ 620990 Екатеринбург, Россия \\ ${ }^{2}$ Институт высокотемпературной электрохимии Уральского отделения Российской академии наук, \\ 620137 Екатеринбург, Россия \\ E-mail: sadovnikov@ihim.uran.ru
}

(Получена 20 фревраля 2018 г. Принята к печати 12 марта 2018 г.)

Определена область термической стабильности размера и фазового состава наночастиц сульфида серебра $\mathrm{Ag}_{2} \mathrm{~S}$. Нанопорошки $\mathrm{Ag}_{2} \mathrm{~S}$ с размером частиц 45-50 нм получены химическим осаждением из водных растворов. Для изучения термической стабильности наночастиц $\mathrm{Ag}_{2} \mathrm{~S}$ нанокристаллические порошки отжигали при нагреве от комнатной температуры до $453 \mathrm{~K}$. Отжиг вплоть до температуры $453 \mathrm{~K}$ не приводит к росту наночастиц и изменению их фазового состава, что позволяет считать этот диапазон температур областью термической стабильности наносостояния сульфида серебра.

DOI: $10.21883 /$ FTP.2018.13.46883.8846

\section{1. Введение}

Основой современной электронной техники являются полупроводники. Наноструктурированные полупроводниковые сульфиды изучаются как перспективные материалы микроэлектроники. Повышение производительности интегральных схем путем наращивания рабочей тактовой частоты приводит к росту тепловыделения транзисторов, которое усиливается экспоненциально. Поэтому важной задачей является определение областей термической стабильности новых полупроводниковых соединений и материалов, включая сульфиды, потенциально пригодных для работы при повышенных температурах. Однако имеющиеся сведения об изменении размера частиц (зерен) сульфидов с температурой ограничены работой [1] по рекристаллизации пленок сульфида кадмия и работой [2] по нанопленкам сульфида свинца. Одним из материалов, рассматриваемых для возможного использования в микроэлектронике, является наноструктурированный сульфид серебpa [3-5]. Он является полупроводником при температуре $<450 \mathrm{~K}$ и суперионным проводником при температуре $>452 \mathrm{~K}$.

Применение наноструктурированного сульфида серебра наиболее перспективно для создания энергонезависимых устройств памяти и резистивных переключателей, в которых используются наногетероструктуры $\mathrm{Ag}_{2} \mathrm{~S} / \mathrm{Ag}$. Их действие основано на восстановлении катионов сульфида серебра $\mathrm{Ag}^{+}$до атомов металлического серебра $\mathrm{Ag}$, обратимом превращении полупроводникового акантита $\alpha-\mathrm{Ag}_{2} \mathrm{~S}$ в суперионный аргентит $\beta-\mathrm{Ag}_{2} \mathrm{~S}$ и возникновении проводящего канала из серебра $\mathrm{Ag}$ и аргентита $\beta-\mathrm{Ag}_{2} \mathrm{~S}[6-8]$.

Как правило, микроэлектронные устройства, элементом которых служит наноструктурированный сульфид серебра, действуют на воздухе в условиях повышенных до (400-450 K) температур, при которых могут происходить рост и изменение фазового состава наночастиц $\mathrm{Ag}_{2} \mathrm{~S}$ и, следовательно, изменение и деградация их функциональных электрических и оптических свойств. Например, по данным [9], максимум флуоресценции при увеличении размера квантовых точек $\mathrm{Ag}_{2} \mathrm{~S}$ от 2.4 до 7.0 нм в коллоидных растворах смещается от 975 до 1175 нм; согласно [4,10], такое же смещение максимума флуоресценции, от $\sim 960$ до $\sim 1176 \mathrm{Hм}$, происходит, когда размер квантовых точек $\mathrm{Ag}_{2} \mathrm{~S}$ растет от 2.3 до 15.0 нм. Наблюдаемое смещение связано с ослаблением эффекта квантового конфайнмента (квантовой локализации) и уменьшением ширины запрещенной зоны $E_{g}$ вследствие увеличения размера квантовых точек $\mathrm{Ag}_{2} \mathrm{~S}$. Это согласуется с экспериментальными данными [11] по размерной зависимости ширины запрещенной зоны нанопорошков $\mathrm{Ag}_{2} \mathrm{~S}$.

Результатом неконтролируемого увеличения размеров квантовых точек и наночастиц $\mathrm{Ag}_{2} \mathrm{~S}$ является нестабильность и деградация свойств устройств и композиций с наноструктурированным сульфидом серебра.

Таким образом, стабильная работа микроэлектронных устройств на основе наноструктурированного сульфида серебра непосредственно зависит от термической стабильности наночастиц $\mathrm{Ag}_{2} \mathrm{~S}$. Однако сведения о термической стабильности размера и фазового состава наночастиц $\mathrm{Ag}_{2} \mathrm{~S}$ отсутствуют. Важную информацию о строении полупроводниковых наноструктур дает спектроскопия комбинационного рассеяния света (КРС), которая является методом идентификации различных соединений серебра, чьи колебательные частоты находятся в ближней инфракрасной области [12,13]. Однако в литературе почти нет работ по спектрам КРС наноструктурированного сульфида серебра. 
Благодаря высокоразвитой поверхности нанопорошки адсорбируют кислород и атмосферную влагу, вследствие чего при их нагреве могут происходить не только рост наночастиц, но также частичная диссоциация сульфида серебра и изменение фазового состава нанопорошка.

В настоящей работе методами высокотемпературной рентгеновской дифракции и комбинационного рассеяния света впервые изучено влияние температуры на размер и фазовый состав частиц нанопорошков $\mathrm{Ag}_{2} \mathrm{~S}$.

\section{2. Образцы и экспериментальные методы}

Нанокристаллический порошок сульфида серебра со средним размером частиц 45-55 нм получали гидрохимическим осаждением из растворов нитрата серебpa $\mathrm{AgNO}_{3}$, сульфида натрия $\mathrm{Na}_{2} \mathrm{~S}$ и цитрата натрия $\mathrm{Na}_{3} \mathrm{C}_{6} \mathrm{H}_{5} \mathrm{O}_{7}$ по ранее описанной методике [4].

Кристаллическую структуру синтезированного и отожженных нанопорошков $\mathrm{Ag}_{2} \mathrm{~S}$ исследовали на дифрактометрах Shimadzu XRD-7000 и STADI-P (STOE) в $\mathrm{Cu} K_{\alpha 1,2}$-излучении в интервале углов $2 \theta=20-95^{\circ}$ с шагом $\Delta(2 \theta)=0.02^{\circ}$ и временем экспозиции $10 \mathrm{c}$ в каждой точке. Определение параметров решетки и окончательное уточнение структуры синтезированных порошков сульфида серебра проводили с помощью программного пакета X'Pert Plus [14].

Исследование in situ влияния отжига на размер наночастиц порошка сульфида серебра в области существования моноклинного акантита $\alpha-\mathrm{Ag}_{2} \mathrm{~S}$ проводили методом высокотемпературной рентгеновской дифракции на дифрактометре X'Pert PRO MPD (Panalytical) с печью Anton Paar HTK-1200 Oven.

Дополнительно нанокристаллический порошок сульфида серебра отжигали в вакууме, при остаточном давлении 0.013 Па, при температурах 393, 423, 453 и $493 \mathrm{~K}$ в течение 2 ч с нагревом до температуры отжига со скоростью не более $1 \mathrm{~K} \cdot$ мин $^{-1}$, а также в аргоне при нагреве до $623 \mathrm{~K}$ в течение 2 ч со скоростью $1 \mathrm{~K} \cdot$ мин $^{-1}$.

Средний размер $D$ частиц (более точно - средний размер областей когерентного рассеяния, ОКР) в тонкодисперсных порошках сульфида серебра оценивали методом рентгеновской дифракции по уширению $\beta(2 \theta)$ дифракционных отражений, используя зависимость приведенного уширения отражений $\beta^{*}(2 \theta)=[\beta(2 \theta) \cos \theta] / \lambda$ от вектора рассеяния $s=2 \sin \theta / \lambda$ [15]. Дифракционные отражения описывали функцией псевдо-фойгта.

Микроструктуру и размер частиц $\mathrm{Ag}_{2} \mathrm{~S}$ изучали методом сканирующей электронной микроскопии (СЭМ) на микроскопе JEOL-JSM LA 6390. Наноструктурированный сульфид серебра был изучен также с помощью просвечивающей электронной микроскопии на микроскопе JEOL JEM-2010 с решеточным разрешением 0.14 нм.
Спектры комбинационного рассеяния света измеряли на микроскопе-спектрометре RENISHAW-1000 (Renishaw plc., UK), оборудованном конфокальным микроскопом Leica DML, нотч-фильтром и CCD камерой, твердотельным лазером LCM-S-111 с длиной волны излучения $532 \mathrm{нм}$, мощностью излучения до $40 \mathrm{MBT}$ в диапазоне от 50 до $4000 \mathrm{~cm}^{-1}$. Спектральное разрешение составляло $1-2 \mathrm{~cm}^{-1}$, размер лазерного пучка 1 мкм, время экспозиции одного спектра менялось от 10 до 30 с, число сканирований (количество циклов накопления сигнала) составляло от 2 до 10.

\section{3. Экспериментальные результаты}

Нагрев нанопорошков сульфида серебра со скоростью $5 \mathrm{~K} \cdot$ мин $^{-1}$ и более в вакууме $(0.013$ Па $=$ $=10^{-4}$ мм рт.ст.) или в атмосфере аргона или гелия при давлении $1.01 \cdot 10^{5}$ Па до температуры $\geq 623 \mathrm{~K}$ сопровождался появлением металлического серебра. На рис. 1 как пример показано изменение рентгенограмм нанопорошка $\mathrm{Ag}_{2} \mathrm{~S}$ после нагрева в атмосфере аргона до $623 \mathrm{~K}$ со скоростью $10 \mathrm{~K} \cdot$ мин $^{-1}$. Согласно дифракционным данным, оба порошка $\operatorname{Ag}_{2} \mathrm{~S}$ в качестве основной фазы содержат моноклинный (пр. гр. $P 2_{1} / c$ ) акантит $\alpha-\mathrm{Ag}_{2} \mathrm{~S}$ (рис. 1). Оценки среднего размера областей когерентного рассеяния $(D)$ нанопорошков были сделаны по уширению не перекрывающихся дифракционных отражений (110), (113), (104) и (031). В результате нагрева размер частиц порошка увеличился от $\sim 45$ до $\sim 147$ нм, в порошке появилось $\sim 3.5 \%$ металлического серебра по массе.

Причиной выделения металлического серебра при быстром нагреве нанопорошка сульфида серебра является окисление части серы в сульфиде кислородом и влагой, адсорбированными поверхностью нанопорошка, удаление серы в виде газообразных оксидов и вследствие этого высвобождение некоторого количества серебра в соответствии с реакцией

$$
\mathrm{Ag}_{2} \mathrm{~S}+\mathrm{O}_{2} \rightarrow 2 \mathrm{Ag}+\mathrm{SO}_{2} \uparrow \text {. }
$$

Выделение серебра при интенсивном нагреве наноструктурированного $\mathrm{Ag}_{2} \mathrm{~S}$ подтвердила спектроскопия комбинационного рассеяния света.

Регистрация спектров КРС нанопорошка $\mathrm{Ag}_{2} \mathrm{~S}$ при максимальной мощности возбуждающего излучения 40 мВт обеспечила высокую интенсивность, но одновременно привела к фотоиндуцированному распаду сульфида серебра, что привело к появлению очень интенсивного пика при $1437 \mathrm{~cm}^{-1}$ и интенсивных пиков при $\sim 490$ и $\sim 1250 \mathrm{~cm}^{-1}$. Согласно [16,17], наблюдаемые сильные пики при $\sim 490, \sim 1250$ и $1437 \mathrm{~cm}^{-1}$ относятся к колебательным модам металлического серебра и оксидных соединений серы, которые выделяются при фотоиндуцированном разложении $\mathrm{Ag}_{2} \mathrm{~S}$ в соответствии с реакцией (1). Действительно, оптическая микроскопия порошка $\mathrm{Ag}_{2} \mathrm{~S}$ после облучения и регистрации спек- 


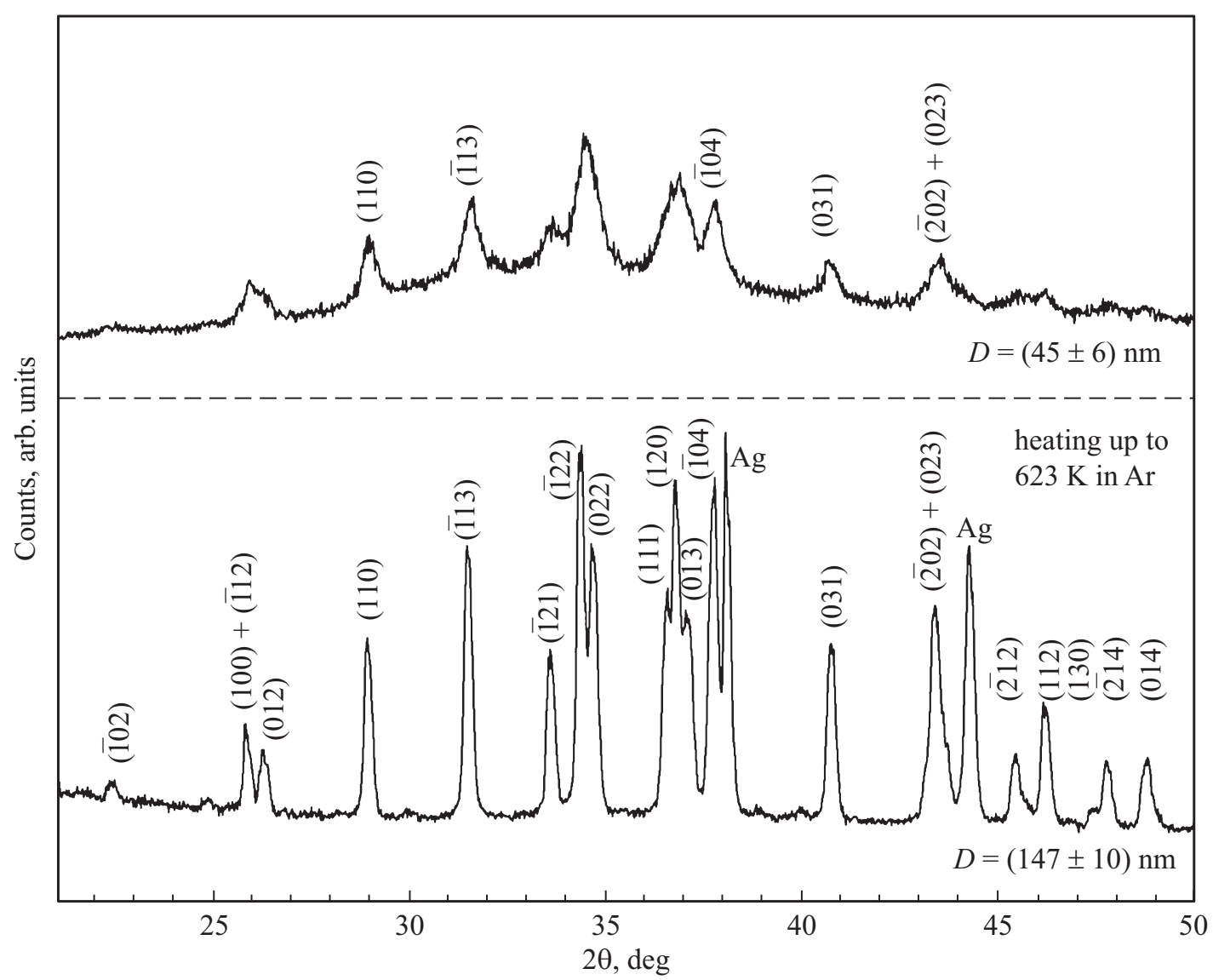

Рис. 1. Рентгенограммы синтезированного нанопорошка сульфида серебра с размером наночастиц $D \approx 45$ нм и того же порошка после нагрева от комнатной температуры до $623 \mathrm{~K}$ в аргоне со скоростью $10 \mathrm{~K} \cdot$ мин $^{-1}$.
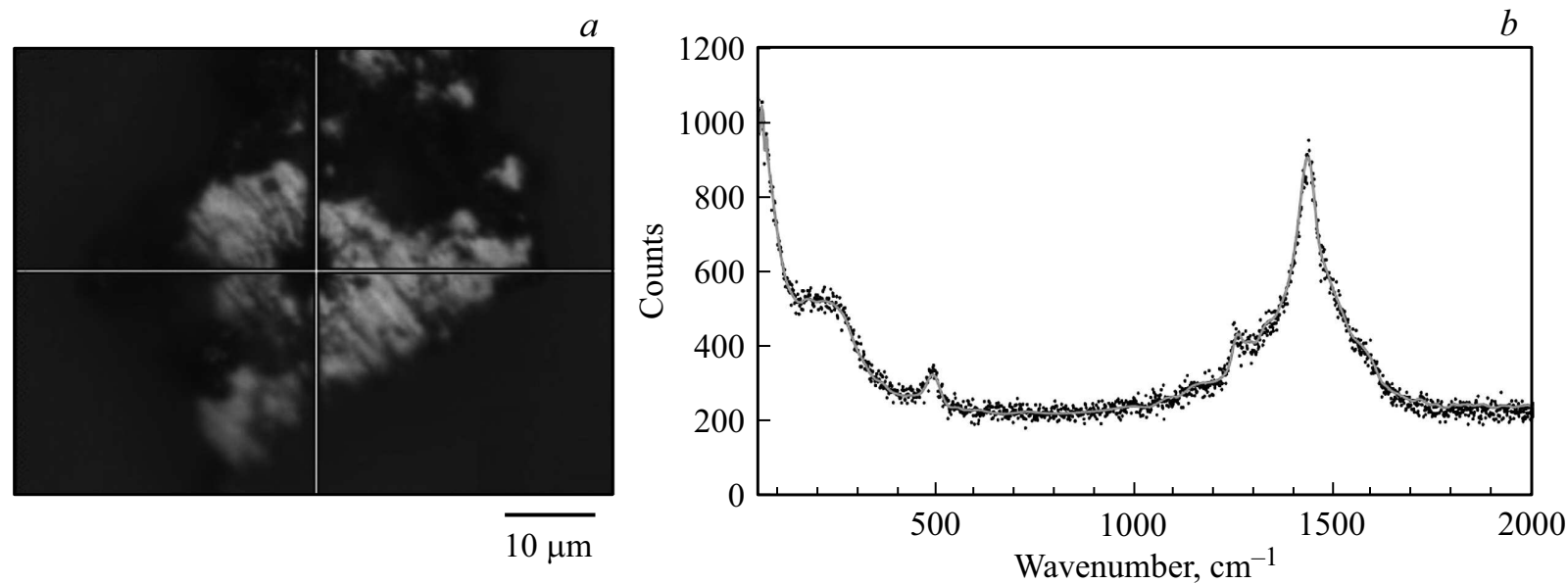

Рис. 2. $a$ - вид образца $\mathrm{Ag}_{2} \mathrm{~S}$ после регистрации спектра КРС при мощности излучения 4 мВт; центральная часть образца, соответствующая области сканирования, как бы выгорела вследствие фотоиндуцированного распада $\mathrm{Ag}_{2} \mathrm{~S}$ на воздухе. $b-$ спектр КРС с полосами при $\sim 490, \sim 1250$ и $\sim 1440 \mathrm{~cm}^{-1}$, связанными с фотоиндуцированным распадом сульфида серебра, выделением металлического серебра $\mathrm{Ag}$ и оксидов серы.

тра КРС показала, что образец в области облучения почернел (рис. 2,a). Даже регистрация спектра при пониженной мощности лазерного излучения 4 мВт $(10 \%$ от максимальной мощности) и при малом числе сканирований не позволила полностью исключить распад
$\mathrm{Ag}_{2} \mathrm{~S}$ и избавиться от связанных с распадом пиков при $\sim 490, \sim 1250$ и $1437 \mathrm{~cm}^{-1}$ (рис. 2, b).

На фоне интенсивных пиков, связанных с фотораспадом сульфида серебра, интенсивность полос, относящихся непосредственно к $\mathrm{Ag}_{2} \mathrm{~S}$, мала. 

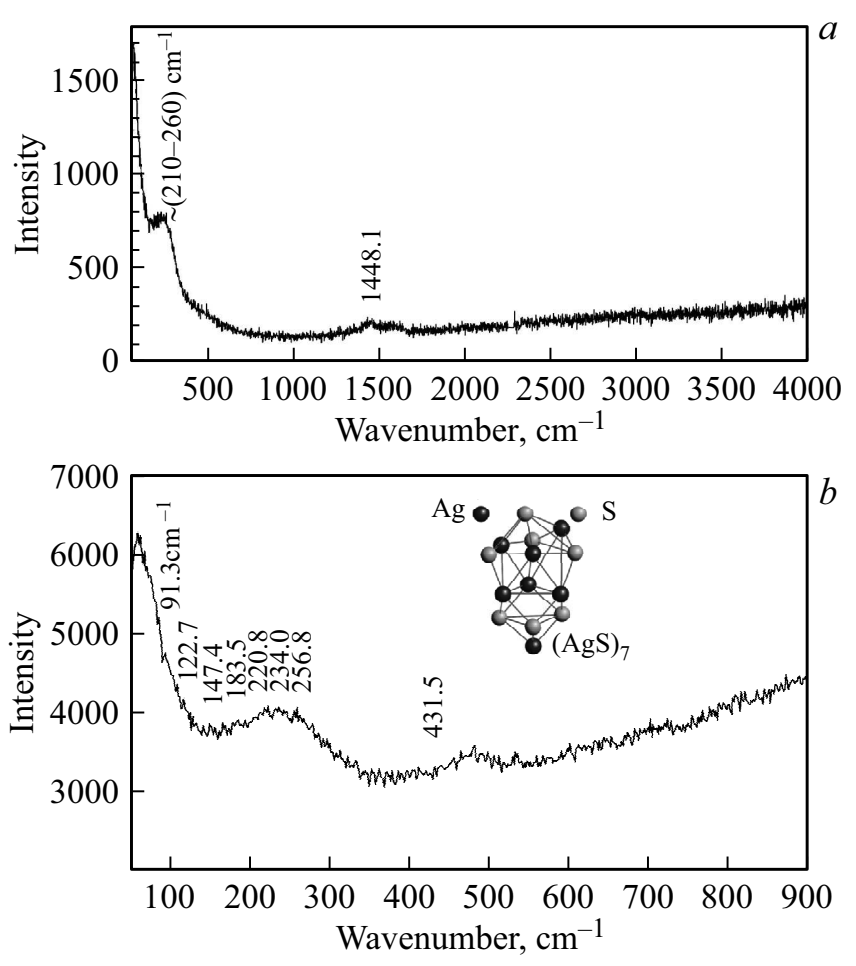

Рис. 3. Спектры КРС нанопорошка $\mathrm{Ag}_{2} \mathrm{~S}$ при комнатной температуре и при разных условиях съемки: $a-$ обзорный спектр, полученный при 2-кратном сканировании образца при мощности излучения $10 \mathrm{MBT} ; b-$ спектр в низкочастотной области, полученный при 10-кратном сканировании образца с мощностью излучения 10 мВт. На вставке $(b)$ показан кластер $(\mathrm{AgS})_{7}$, чьи радиальные колебания, согласно [20], преимущественно обусловливают полосы, наблюдаемые в спектре КРС наночастиц $\mathrm{Ag}_{2} \mathrm{~S}$ в области вблизи $250 \mathrm{~cm}^{-1}$.

Обзорный спектр КРС нанопорошка $\mathrm{Ag}_{2} \mathrm{~S}$, полученный при мощности возбуждающего излучения $10 \mathrm{MBT}$ ( $25 \%$ от максимальной мощности) и всего лишь двух сканированиях образца, показан на рис. $3, a$. Он подобен спектру тонкозернистого порошка сульфида серебра с моноклинной структурой акантита, представленному в работе [16]. Спектр КРС нанопорошка $\alpha-\mathrm{Ag}_{2} \mathrm{~S}$ в низкочастотной области $210-260 \mathrm{~cm}^{-1}$ размыт и уширен. Для более детального анализа на рис. $3, b$ показан спектр нанопорошка $\alpha-\mathrm{Ag}_{2} \mathrm{~S}$ в низкочастотной области, записанный при 10-кратном сканировании образца и мощности излучения $10 \mathrm{мB}$.

В спектре КРС (рис. 3,b) можно наблюдать серию полос в диапазоне $90-260 \mathrm{~cm}^{-1}$, обусловленных в основном связями $\mathrm{Ag}-\mathrm{S}$. Это согласуется с литературными данными $[17,18]$, согласно которым спектр КРС акантита $\alpha-\mathrm{Ag}_{2} \mathrm{~S}$ характеризуется интенсивными полосами при $\sim 93, \sim 122,167-188,225-253$ и $\sim 430 \mathrm{~cm}^{-1}$. Согласно $[18,19]$, пик при $\sim 430 \mathrm{~cm}^{-1}$ соответствует непосредственно низкотемпературному моноклинному акантиту $\alpha-\mathrm{Ag}_{2} \mathrm{~S}$. Наличие широкой полосы в области $210-260 \mathrm{~cm}^{-1}$, центрированной около $240 \mathrm{~cm}^{-1}$, согласуется также с данными работы [20], в которой пик, вызванный наночастицами $\mathrm{Ag}_{2} \mathrm{~S}$, наблюдался вблизи $220 \mathrm{~cm}^{-1}$. В структуре акантита $\alpha-\mathrm{Ag}_{2} \mathrm{~S}$ трехатомные цепочки $\mathrm{Ag}-\mathrm{S}-\mathrm{Ag}$ являются нелинейными, поэтому полосы спектра связаны с симметричными продольными колебательными модами $\mathrm{Ag}-\mathrm{S}-\mathrm{Ag}$. В работе [20] наночастицы $\mathrm{Ag}_{2} \mathrm{~S}$ моделировали совокупностью кластеров $(\mathrm{AgS})_{n} \mathrm{c} n=1-9$, имеющих минимальную энергию. Кластеры $(\mathrm{AgS})_{n}$ были образованы разным числом парных связей $\mathrm{Ag}-\mathrm{S}$. В результате моделирования с использованием приближений теории функционала плотности было показано, что полосы, наблюдаемые в спектре КРС наночастиц $\mathrm{Ag}_{2} \mathrm{~S}$ в области $\sim 250 \mathrm{~cm}^{-1}$, преимущественно обусловлены радиальными колебаниями кластера $(\mathrm{AgS})_{7}$ (см. вставку на рис. 3 ), а также кластеров $(\mathrm{AgS})_{6}$ и $(\mathrm{AgS})_{8}$ [20]. Согласно [19,21], фундаментальные моды, которые наблюдаются при $\sim 220$ и $\sim 430 \mathrm{~cm}^{-1}$, соответствуют продольным оптическим фононным колебаниям первого и второго порядков в $\mathrm{Ag}_{2} \mathrm{~S}$ соответственно.

Для того чтобы избежать при температурных измерениях потери части серы и обусловленного этим выделения металлического серебра, нанопорошки сульфида серебра предварительно отжигали в вакууме $\left(0.013\right.$ Па $=10^{-4}$ мм рт. ст.). Медленный нагрев в вакууме до температуры отжига $393 \mathrm{~K}$ проводили в течение 2 ч, т.е. со скоростью $0.5 \mathrm{~K} \cdot$ мин $^{-1}$, затем нанопорошки 2 ч отжигали при температуре $393 \mathrm{~K}$ в вакууме. По данным дифференциального термического анализа при нагреве отожженных нанопорошков сульфида серебра потери массы нет.

Последующее влияние температуры отжига на размер наночастиц изучали на отожженных нанопорошках сульфида серебра.

Рентгенограммы нанокристаллического сульфида серебра, зарегистрированные на воздухе при температуpax 295, 323, 348, 373, 398 и $423 \mathrm{~K}$ (рис. 4), содержат одинаковый набор уширенных дифракционных отражений, соответствующих нестехиометрическому моноклинному (пр. гр. $P 2_{1} / c$ ) акантиту $\alpha-\mathrm{Ag}_{1.93-1.98} \mathrm{~S}$ [4]. Средний размер областей когерентного рассеяния в исходном нанопорошке равен $D=(44 \pm 6)$ нм и согласуется с размером наночастиц по данным сканирующей электронной микроскопии. Последовательный нагрев нанопорошка до $423 \mathrm{~K}$ в пределах ошибок измерений не привел к сколько-нибудь заметному сужению дифракционных отражений, т.е. не сопровождался увеличением размера наночастиц. Согласно сделанным оценкам, средний размер ОКР в нанопорошке акантита при температурах 398 и $423 \mathrm{~K}$ составляет $(46 \pm 6)$ и $(47 \pm 6)$ нм. Изменений фазового состава нанопорошков при нагреве и отжиге не было.

С учетом ошибок оценки размера $D$ 2-часовой отжиг при температуре до $423 \mathrm{~K}$ не привел к росту размера наночастиц. Слабый рост размера ОКР до 58 и 72 нм наблюдался только для нанопорошков, отожженных при более высоких температурах, 453 и $493 \mathrm{~K}$ соответственно. В нанопорошке, отожженном при $623 \mathrm{~K}$ в 


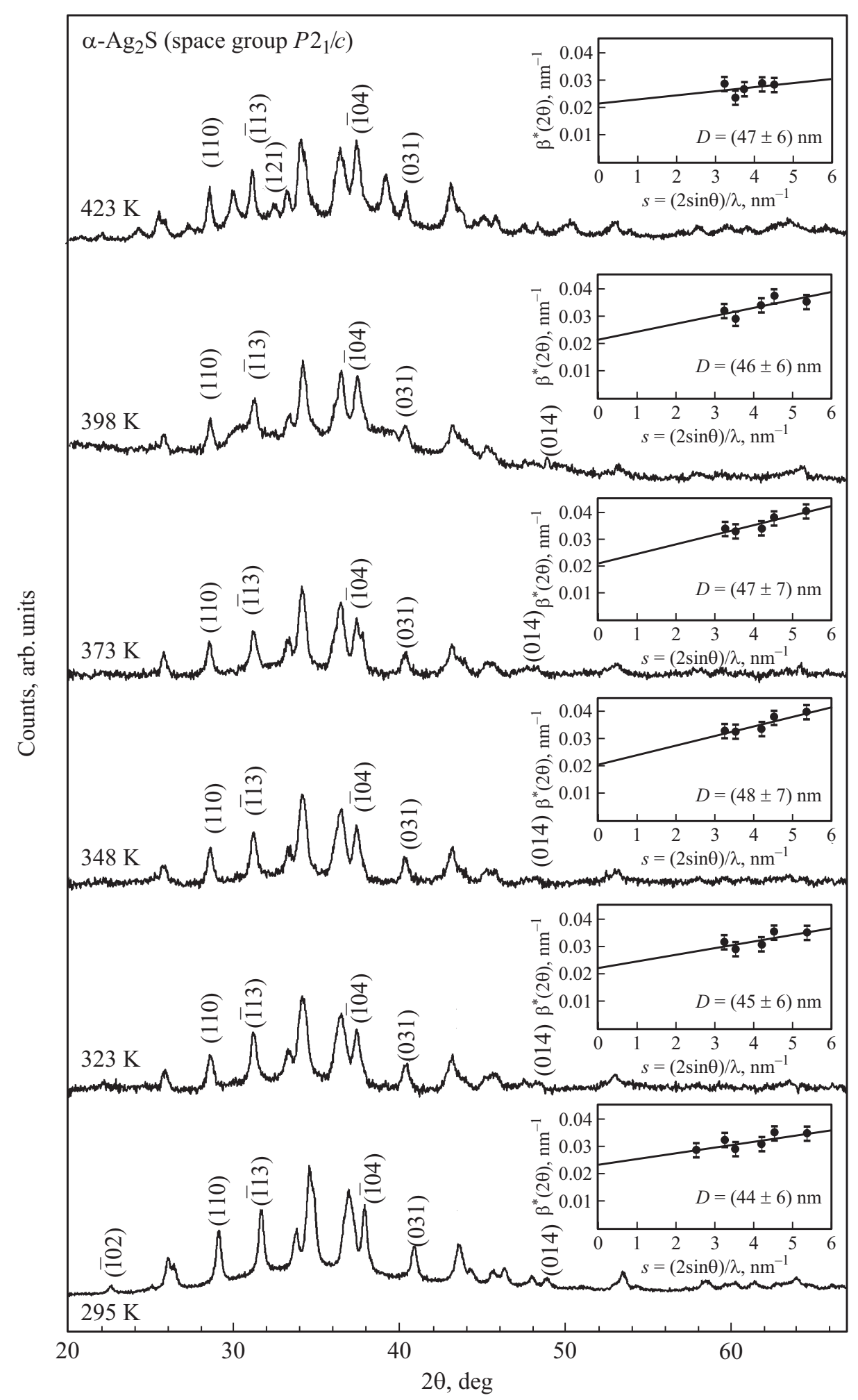

Рис. 4. Рентгенограммы нанокристаллического акантита $\alpha-\mathrm{Ag}_{2} \mathrm{~S}$ при нагреве от 300 до $423 \mathrm{~K}$. На вставках показана оценка среднего размера областей когерентного рассеяния по уширению неперекрывающихся дифракционных отражений.

течение 2 ч, размер частиц составил $D=(147 \pm 10)$ нм (см. рис. 1).

Изменение размера наночастиц $\mathrm{Ag}_{2} \mathrm{~S}$ в зависимости от температуры вакуумного отжига показано на рис. 5 .
В области температур отжига $<440 \mathrm{~K}$ размер наночастиц с увеличением температуры с учетом ошибок измерений почти не меняется, поэтому интервал температур 273-443 K можно рассматривать как область тер- 

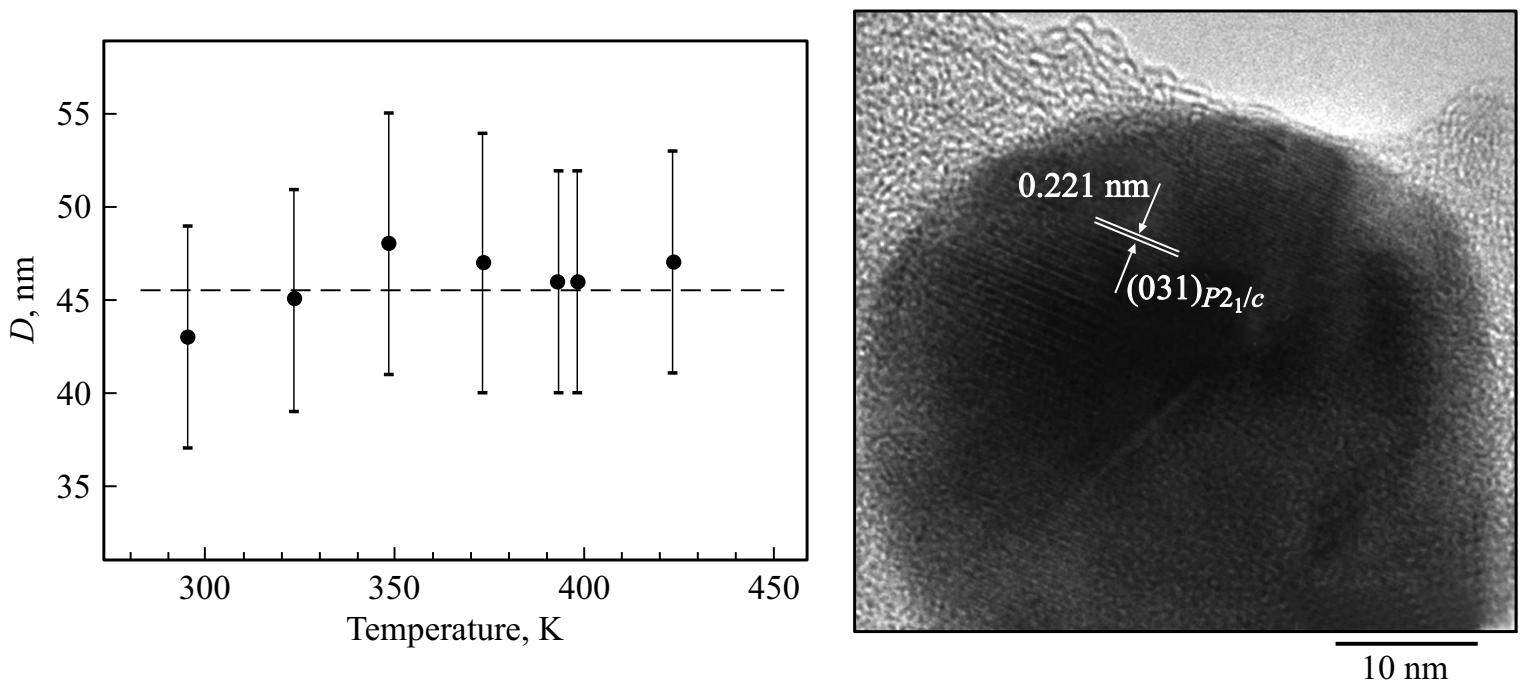

Рис. 5. Влияние температуры отжига на размер $D$ наночастиц порошка $\mathrm{Ag}_{2} \mathrm{~S}$. Справа показано ТЕМ-изображение наночастицы $\mathrm{Ag}_{2} \mathrm{~S}$ размером $\sim 40 \mathrm{Hм}$.

мической стабильности размера наночастиц $\mathrm{Ag}_{2} \mathrm{~S}$. Это означает, что электронные устройства на основе наноструктурированного сульфида серебра могут стабильно работать в этом интервале температур. Наблюдаемый рост наночастиц происходит при температурах $>455 \mathrm{~K}$, хотя даже в диапазоне температур $460-930 \mathrm{~K}$ частицы сульфида серебра сохраняют наноразмерный масштаб и не достигают микрометрового размера.

Нужно отметить, что термическая стабильность размера наночастиц $\mathrm{Ag}_{2} \mathrm{~S}$ меньше, чем наночастиц сульфида свинца $\mathrm{PbS}$ [2]. Для сульфида серебра $\mathrm{Ag}_{2} \mathrm{~S}$ рост наночастиц начинается при температуре $\sim 460 \mathrm{~K}$, тогда как наночастицы сульфида свинца $\mathrm{PbS}$ начинают расти при температуре $\sim 700 \mathrm{~K}$. По-видимому, меньшая область термической стабильности размера наночастиц $\mathrm{Ag}_{2} \mathrm{~S}$ обусловлена меньшей температурой плавления сульфида серебра (1115 и $1391 \mathrm{~K}$ для крупнозернистых $\mathrm{Ag}_{2} \mathrm{~S}$ и $\mathrm{PbS}$ соответственно). Другой причиной меньшей термической стабильности наночастиц $\mathrm{Ag}_{2} \mathrm{~S}$ может быть наличие в сульфиде серебра фазового превращения при $\sim 450 \mathrm{~K}$; в сульфиде свинца полиморфных фазовых превращений нет.

\section{4. Заключение}

Изучение влияния температуры отжига на размер частиц нанопорошков сульфида серебра показало, что увеличение температуры вплоть до $\sim 450 \mathrm{~K}$ не приводит к росту наночастиц и изменению их фазового состава, что позволяет считать этот диапазон температур областью термической стабильности нанокристаллического порошка сульфида серебра. Благодаря термической стабильности размера наночастиц электронные устройства на основе наноструктурированного сульфида серебра могут стабильно работать в этом интервале температур.

Исследование выполнено при финансовой поддержке Российского научного фонда (проект № 14-23-00025) в ИХТТ УрО РАН. При выполнении работы использовано оборудование Центра коллективного пользования „Состав вещества“ ИВТЭ УрО РАН.

\section{Список литературы}

[1] W. Kahle, H. Berger. Phys. Status Solidi A, 2, 717 (1970).

[2] С.И. Садовников, Н.С. Кожевникова, А.А. Ремпель. Неорг. матер., 47, 929 (2011).

[3] A. Tang, Yu. Wang, H. Ye, C. Zhou, C. Yang, X. Li, H. Peng, F. Zhang, Y. Hou, F. Teng. Nanotechnology, 24, 355602 (2013).

[4] S.I. Sadovnikov, A.A. Rempel, A.I. Gusev. Nanostructured Lead, Cadmium and Silver Sulfides: Structure, Nonstoichiometry and Properties (Cham-Heidelberg, Springer Intern. Publ. AG, 2018).

[5] S.I. Sadovnikov, A.A. Rempel, A.I. Gusev. Russ. Chem. Rev., 87, 303 (2018).

[6] K. Terabe, T. Hasegawa, T. Nakayama, M. Aono. Nature, 433, 47 (2005).

[7] C.H. Liang, K. Terabe, T. Hasegawa, M. Aono. Nanotechnology, 18 (48), 485202 (2007).

[8] D. Wang, L. Liu, Y. Kim, X. Huang, D. Pantel, D. Hesse, M. Alexe. Appl. Phys. Lett., 98, 243109 (2011).

[9] Y. Zhang, Y. Liu, C. Li, X. Chen, Q. Wang. J. Phys. Chem. C, 118, 4918 (2014).

[10] S.I. Sadovnikov, A.I. Gusev. J. Mater. Chem. A, 5, 17676 (2017).

[11] S.I. Sadovnikov, Yu.V. Kuznetsova, A.A. Rempel. Nanostr. Nano-Object., 7, 81 (2016).

[12] T. Jawhari. Analysis, 28, 15 (2000).

[13] В.Н. Стрекаловский, Э.Г. Вовкотруб, А.Б. Салюлев. Аналитика и контр., 4, 334 (2000). 
[14] X'Pert Plus Version 1.0. Program for Crystallography and Rietveld analysis Philips Analytical B. V. OKoninklijke Philips Electronics N. V.

[15] A.I. Gusev, A.A. Rempel. Nanocrystalline Materials (Cambridge, Cambridge Intern. Sci. Publ., 2004).

[16] I. Martina, R. Wiesinger, D. Jembrih-Simbürger, M. Schreiner. E-Preserv. Sci. (Morana RTD), 9, 1 (2012).

[17] J.I. Lee, S.M. Howard, J.J. Kellar, K.N. Han, W. Cross. Metall. Mater. Trans. B, 32, 805 (2001).

[18] A.N. Belov, O.V. Pyatilova, M.I. Vorobiev. Advanc. Nanoparticles, 3, 1 (2014).

[19] M. Osada, K. Terabe, C. Liang, T. Hasegawa. In: 214th ECS Meeting Abstr. MA 2008-2 (214th ECS Metting, Honolulu, 2008) Abstract 1406.

[20] Y. Delgado-Beleño, M. Cortez-Valadez, C.E. Martinez-Nuñez, R. Britto Hurtado, A.B. Alvarez Ramón, O. Rocha-Rocha, H. Arizpe-Chávez, A. Perez-Rodríguez, M. Flores-Acosta. Chem. Physics, 463, 106 (2015).

[21] L. Hashmi, P. Sana, M.M. Malik, A.H. Siddiqui, M.S. Qureshi. Nano Hybrides, 1, 23 (2012).

Редактор Л.В. Шаронова

\title{
Determination of thermal stability region of size and phase composition of semiconductor silver sulfide nanoparticles
}

\author{
S.I. Sadovnikov ${ }^{1}$, E.G. Vovkotrub ${ }^{2}$ \\ ${ }^{1}$ Institute of Solid State Chemistry, \\ Ural Division of Russian Academy of Sciences, \\ 620990 Ekaterinburg, Russia \\ ${ }^{1}$ Institute of High-Temperature Electrochemistry, \\ Ural Branch of Russian Academy of Sciences, \\ 620137 Ekaterinburg, Russia
}

\footnotetext{
Abstract The region of thermal stability of a size and phase composition of the silver sulfide nanoparticles $\mathrm{Ag}_{2} \mathrm{~S}$ has been determined. Nanopowders $\mathrm{Ag}_{2} \mathrm{~S}$ with the particle size of $45-50 \mathrm{~nm}$ were prepared by chemical deposition from aqueous solutions. To study the thermal stability of the $\mathrm{Ag}_{2} \mathrm{~S}$ nanoparticle sizes, the nanocrystalline powders have been annealed during heating from room temperature to $453 \mathrm{~K}$. Annealing at the temperatures up to $453 \mathrm{~K}$ did not lead to increase of nanoparticles and change of their phase composition. It allows considering this temperature interval as the region of thermal stability of the $\mathrm{Ag}_{2} \mathrm{~S}$ nanoparticles.
} 